\title{
PHYSIOLOGIC ACTION OF CLOSTRIDIUM OEDEMATIENS (NOVYI) TOXIN IN DOGS ${ }^{1,2,3}$
}

\author{
By JOSEPH C. AUB, PAUL C. ZAMECNIK, ANd IRA T. NATHANSON \\ (From the Medical Laboratories of the Collis P. Huntington Memorial Hospital of Harvard \\ University at the Massachusetts General Hospital, Boston, Massachusetts)
}

(Received for publication September 25, 1946)

The frequent occurrence of $\mathrm{Cl}$. oedematiens in war wounds in general and in gas gangrene in particular (1) has stimulated the study of the physiologic effects of the toxin of this organism. The àvailability of $\mathrm{Cl}$. oedematiens toxin in purified form has made it possible to investigate its action as distinct from toxins of other synergistic and symbiotic organisms which contribute to the clinical picture of anaerobic infections. Such a study is herein reported.

The pathologic effects of $\mathrm{Cl}$. oedematiens were described first by Novy (2); and, subsequently, on the same or closely related organisms, by Weinberg and Seguin (3), and others (4 to 6). Previous studies of the physiologic effects of this toxin have not, however, reached our attention. It has not been demonstrated that more than one toxin is produced by the organism, although analogy with $\mathrm{Cl}$. welchii makes this a possibility.

Recent work from this laboratory ( 7 to 13 ) has shown that the presence of clostridia may constitute an important factor in some forms of traumatic shock produced experimentally in dogs. The present communication points out that a picture similar to that of traumatic shock may be produced experimentally in dogs by the injection of $\mathrm{Cl}$. oedematiens toxin.

\section{MATERIALS AND METHODS}

The experiments have been carried out using several preparations of purified $\mathrm{Cl}$. oedematiens (Novyi) toxin. ${ }^{4}$

1 This is publication No. 631 of the Cancer Commission of Harvard University, and No. IX in the series entitled "The Toxic Factors in Experimental Traumatic Shock."

2 The work described in this paper was done under a contract, recommended by the Committee on Medical Research, between the Office of Scientific Research and Development and the Massachusetts General Hospital.

${ }^{3}$ Grateful acknowledgment is due the Josiah Macy, Jr. Foundation for a grant for the histopathological studies.

4 These preparations were made available to us by Professor Milan A. Logan.
The toxins were prepared by ammonium sulfate fractionation of toxic filtrates of $\mathrm{Cl}$. oedematiens strain N21B of the Lederle Laboratories. They remained stable over a period of months when kept in dry form over phosphorus pentoxide at $4^{\circ} \mathrm{C}$. The toxins assayed 500 to 2,500 mouse MLD (subcutaneous $\mathrm{LD}_{50}$ ) per mgm. dry powder. Aliquots of dry powder were weighed out as needed and were dissolved in $5 \mathrm{ml}$. of $0.18 \mathrm{M}$ phosphate buffer and 0.9 per cent sodium chloride, $\mathrm{pH}$ 7.2. Further dilutions were made with 0.9 per cent sodium chloride. These solutions were always used within an hour of their preparation.

The methods used in this study have been described previously (14), with the following exceptions: liver function was tested by the bromsulfalein excretion method; and kidney function was tested by phenolsulfonphthalein excretion.

\section{RESULTS}

\section{Cl. oedematiens intravenously}

Dosage: Thirty-five dogs were injected intravenously with a dosage of toxin which ranged from 3,700 down to 20 MLD per $\mathrm{kgm}$. Of 9 unanesthetized dogs simply injected with varying amounts of toxin and then observed, there was only 1 survivor, the animal receiving the $20 \mathrm{MLD}$ per kgm. dose. Dogs given 46 and 90 MLD per $\mathrm{kgm}$. died on the third day. With larger doses of toxin (over 500 MLD per kgm.) the survival time was uniformly shortened to a matter of hours.

Twenty-six dogs were anesthetized and, following carotid and tracheal cannulation, were injected intravenously with toxin. The majority of these animals were given 1,250 MLD per kgm., and only 3 out of the 26 survived longer than 8 hours.

Rate of injection: There was no great differ-. ence in the effect of the toxin whether it was given rapidly in small volume (less than $10 \mathrm{ml}$.) by syringe, or diluted to $100 \mathrm{ml}$. and allowed to drip into the animal by slow infusion over a period of hours. The survival time following slow infusion was an hour or two longer, and the decline of the blood pressure more gradual, but otherwise the picture was the same by either method.

Clinical course: (Dose of toxin, 125 to 3,750 
MLD per kgm., sodium pentobarbital anesthesia, $30 \mathrm{mgm}$. per $\mathrm{kgm}$. Period of observation up to 8 hours after toxin injection.) There was a latent period of approximately 1 hour, after injection of the toxin, during which no abnormal change was noted in the animal. The first changes were noted in the cardiac output, which commenced to fall after the first hour and continued to do so progressively until death. The total peripheral vascular resistance rose concomitantly with the fall in cardiac output. The blood pressure did not decline significantly, however, until much laterseveral hours after the administration of the toxin. No significant change occurred in the whole blood hemoglobin or hematocrit levels. Plasma volume dropped late in the course of the disease. There was no hemolysis. The relationship of these findings is summarized in Table $I$.

Electrocardiograms done in 2 dogs showed no significant change. There was no consistent change in temperature in 29 dogs, but both pulse and respiratory rates increased as the cardiac output fell. In an effort to determine whether myocardial failure was an important part of the picture of $\mathrm{Cl}$. oedematiens toxemia, the effect of an additional burden of transfused blood and of albumin on the cardiac output was tested. Seven dogs, given 1,200 to 1,500 MLD per $\mathrm{kgm}$. doses of toxin, were transfused with compatible, defibrinated blood after the cardiac output had fallen considerably and the blood pressure had commenced to fall. Six dogs were transfused with purified bovine albumin ${ }^{5}$ under similar circumstances. The amount of fluid administered ranged from 25 per cent up to 100 per cent of the estimated blood volume. It was noted (a) that the blood pressure always rose promptly, but fell within a few minutes after termination of the transfusion; $(b)$ that right auricular pressure remained low even when the transfusion was given at a rate of 10 to $15 \mathrm{ml}$. per minute; and $(c)$ that the cardiac output invariably rose transiently after the transfusion, although it just as invariably fell promptly after the transfusion. This evidence all pointed to the intactness of the myocardium.

The results of a typical experiment and the interrelationship of the various data are illustrated in

\footnotetext{
5 The authors are indebted to Professor Edwin J. Cohn for generous supplies of purified bovine albumin.
}

Figure 1. It is to be observed that the blood volume was lower than previously, in spite of the administration of a large volume of blood. It was consistently found that blood or plasma given to an animal following a lethal dose of toxin did not prolong life appreciably. Such fluid appeared to be lost rapidly from the actively circulating blood volume, and to increase the hemorrhage and edema present in various organs.

Efforts to prevent or delay the fatal outcome by administration of adrenal cortical extract or lanatoside $C$ were unsuccessful.

Hepatic clearance of bromsulfalein was followed in 2 dogs after injection of toxin; in one case, the rate of dye excretion per 20 minutes decreased from 60 to 30 per cent ; in the other case, there was a decrease from 81 to 36 per cent.

Renal clearance of phenolsulfonphthalein was performed in 2 dogs. In both cases the control clearance was $70 \mathrm{ml}$. per minute. Three and onehalf hours after toxin administration the clearance was $5 \mathrm{ml}$. per minute in one case and none in the other. As the experiment progressed, there was a decrease in urinary output. (From the above clearance tests it is impossible to decide what part of the decrease in excretory function to ascribe to decreased blood flow through the organ, and what part to damage to parenchymal cells.)

Antitoxin: Nine dogs were injected first with $\mathrm{Cl}$. oedematiens toxin, then with $\mathrm{Cl}$. oedematiens antitoxin, as contained in a polyvalent antitoxin. ${ }^{\circ}$ The dosage of $\mathrm{Cl}$. oedematiens antitoxin ranged from 500 to 2,300 antitoxin units, which provided a 50 to 200-fold excess of antitoxin over the toxin given. The results indicated that antitoxin given 5 minutes after the rapid injection by syringe of a single dose of 1,250 MLD of toxin per kgm. protected the animal completely. Antitoxin given 15 minutes after a similar injection of toxin, however, failed in 5 out of 5 dogs to prevent a lethal outcome. In 4 instances, the toxin was administered by intravenous drip over a period of 1 to 2 hours, and antitoxin was given immediately thereafter. Three out of 4 dogs died within 5 hours after the antitoxin had been administered.

In one instance, toxin was given subcutaneously, and antitoxin was given intravenously 15 minutes later. The antitoxin did not prevent the develop-

\footnotetext{
6 Lederle's polyvalent gas gangrene antitoxin.
} 


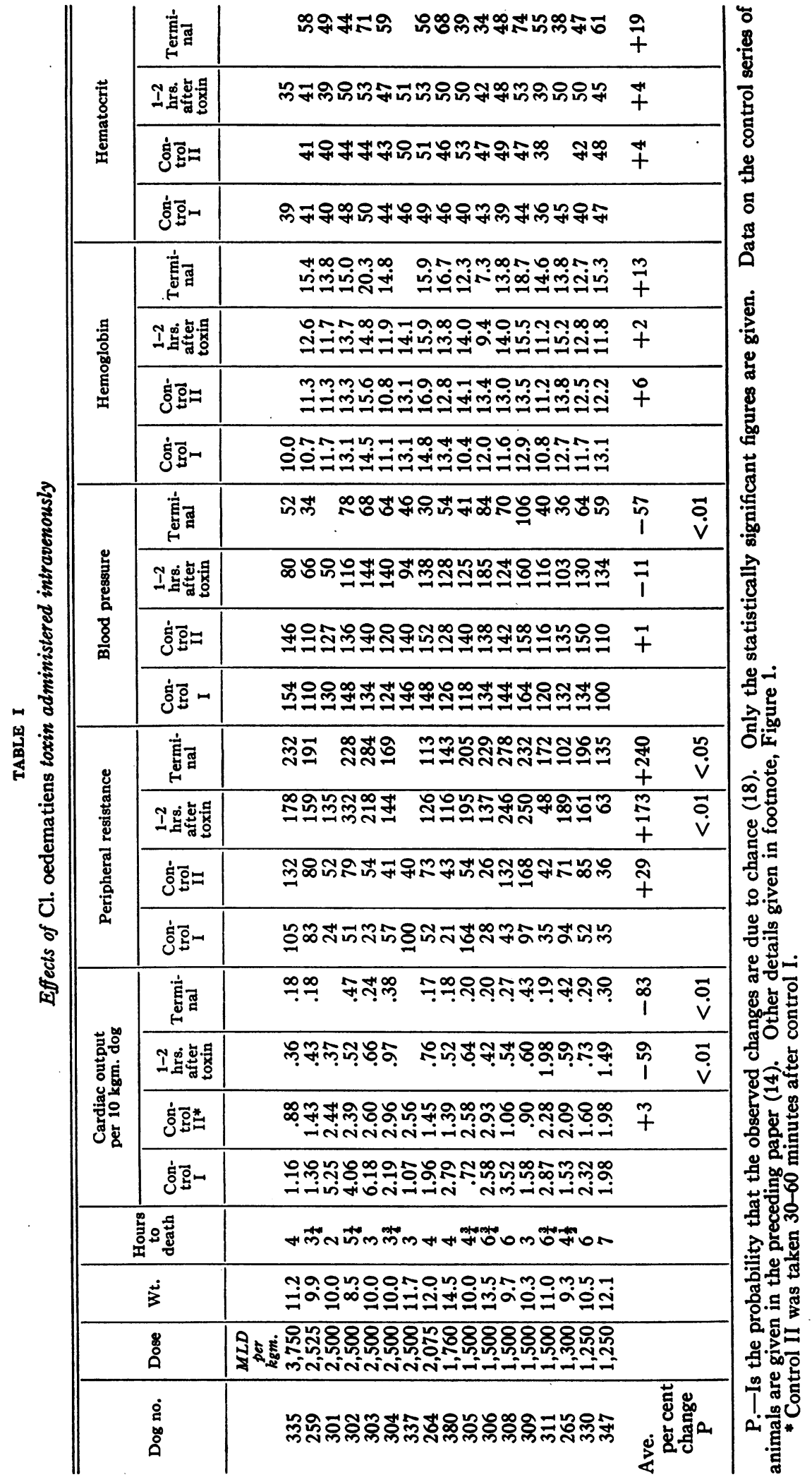




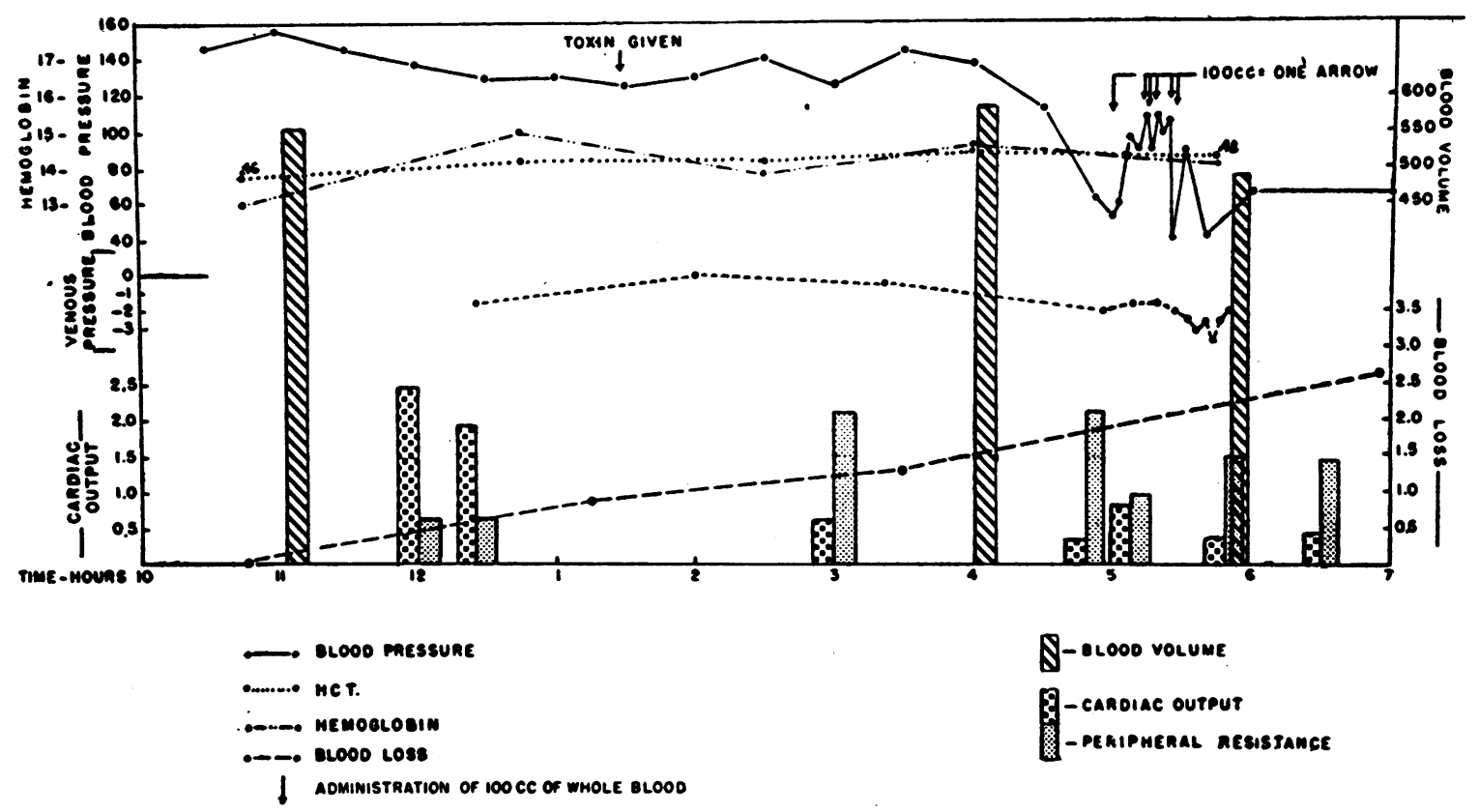

Fig. 1. Effects of $\mathrm{Cl}$. oedematiens Toxin Administered Intravenously

The cardiac output is expressed in liters per minute. The relative peripheral vascular resistance is expressed in arbitrary units as the quotient: blood pressure in $\mathrm{mm}$. mercury/cardiac output in liters per minute. The hemoglobin is expressed as grams per cent. The blood volume is given in cubic centimeters, and the blood loss as per cent of body weight.

ment of a massive edema, which spread from the injection site.

Pathology: ${ }^{7}$ The gross autopsy findings associated with intravenous administration of $\mathrm{Cl}$. oedematiens toxin in lethal dosage to non-immunized dogs consisted of the following : edema and hemorrhage into the lungs; congestion of the liver; hemorrhage into the adrenals; congestion and submucosal hemorrhage into the small intestine, particularly into the duodenum; small, subendothelial hemorrhages into the cardiac musculature, especially near the attachments of the chordae tendineae. The spleen was uniformly small and contracted. The weights of organs in animals receiving $\mathrm{Cl}$. oedematiens and $\mathrm{Cl}$. welchii toxins have been recorded in Table II. The liver, lungs, and small intestine showed significant increases in weight, and the spleen a significant decrease,

7 According to Doctor A. C. Ivy (15), the capillaries of the duodenum of the dog have been known to be especially sensitive to various toxic substances ingested or produced in the body. The peculiar blood supply of the villi in the duodenal mucosa in the dog (16) appears to offer the best explanation of this phenomenon. when a lethal dose of $\mathrm{Cl}$. oedematiens toxin was given intravenously. If the average change in organ weight is used it appears that there is an increase in weight of the above organs, including the spleen, totalling 2.1 per cent of the body weight. This weight increase, if due to trapping and extravasation of blood into these organs, could represent 20 per cent of the total blood volume.

The microscopic sections revealed a marked engorgement throughout the lungs and viscera, particularly in the former. ${ }^{8}$ Capillaries and venules in the submucosal region of the duodenum were extraordinarily dilated and engorged with blood. The mucosa and submucosa of the stomach were spared, and a clear-cut line of demarkation appeared at the pylorus between the relatively normal pallor of the stomach and the red blush of the duodenal mucosa.

Immunized animals (17) injected intravenously with a lethal dose of $\mathrm{Cl}$. oedematiens toxin revealed little if any engorgement of blood vessels

8 The authors are indebted to Dr. Benjamin Castleman for reviewing and interpreting the microscopic findings. 
TABLE II

Mean organ weights, recorded as per cent of body weight

\begin{tabular}{|c|c|c|c|c|c|c|c|c|c|c|c|c|c|c|c|c|c|c|}
\hline & \multicolumn{3}{|c|}{ Liver } & \multicolumn{3}{|c|}{ Spleen } & \multicolumn{3}{|c|}{ Small intestine } & \multicolumn{3}{|c|}{ Lungs } & \multicolumn{3}{|c|}{ Heart } & \multicolumn{3}{|c|}{ Kidneys } \\
\hline & $\mathrm{n}$ & Mean & $\sigma$ & $\mathbf{n}$ & Mean & $\sigma$ & $\mathbf{n}$ & Mean & $\sigma$ & $\mathbf{n}$ & Mean & $\sigma$ & $\mathbf{n}$ & Mean & $\sigma$ & $\mathbf{n}$ & Mean & $\sigma$ \\
\hline $\begin{array}{l}\text { Controls } \\
\text { Cl. welchii-I.M. } \ddagger \\
\text { Cl. welchii-I.V. } \neq \\
\text { Cl. oedematiens-I.M. } \\
\text { Cl. oedematiens-I.V. }\end{array}$ & $\begin{array}{r}11 \\
17 \\
7 \\
4 \\
12\end{array}$ & $\begin{array}{l}4.0 \\
3.4 \\
4.3 \\
3.5 \\
4.9 \dagger\end{array}$ & $\begin{array}{r}.84 \\
.65 \\
1.20 \\
.28 \\
.69\end{array}$ & $\begin{array}{r}11 \\
17 \\
5 \\
2 \\
11\end{array}$ & $\begin{array}{l}.55 \\
.44 \\
.95 \\
.53 \\
.37^{*}\end{array}$ & $\begin{array}{l}.15 \\
.19 \\
.27 \\
.17 \\
.08\end{array}$ & $\begin{array}{r}11 \\
14 \\
3 \\
2 \\
10\end{array}$ & $\begin{array}{l}3.0 \\
2.9 \\
2.6 \\
3.2 \\
3.6 \dagger\end{array}$ & $\begin{array}{l}.38 \\
.66 \\
.50 \\
.60 \\
.21\end{array}$ & $\begin{array}{r}10 \\
12 \\
5 \\
3 \\
6\end{array}$ & $\begin{array}{l}1.05 \\
1.08 \\
1.55^{*} \\
1.48 \\
1.87^{*}\end{array}$ & $\begin{array}{l}.13 \\
.48 \\
.12 \\
.64 \\
.64\end{array}$ & $\begin{array}{r}5 \\
12 \\
5 \\
3 \\
6\end{array}$ & $\begin{array}{l}.88 \\
.83 \\
.83 \\
.85 \\
.87\end{array}$ & $\begin{array}{l}.01 \\
.33 \\
.13 \\
.23 \\
.18\end{array}$ & $\begin{array}{r}10 \\
12 \\
5 \\
3 \\
6\end{array}$ & $\begin{array}{l}.65 \\
.63 \\
.79 \\
.56 \\
.65\end{array}$ & $\begin{array}{l}.11 \\
.09 \\
.19 \\
.15 \\
.09\end{array}$ \\
\hline
\end{tabular}

I.M. = Intramuscularly.

I.V. = Intravenously.

$*$ = Difference from control value significant $(\mathrm{p}<.01)(20)$.

$\dagger=$ Difference from control value probably significant $(p<.05)$.

$\ddagger=$ Details of these experiments are given elsewhere (14).

$\tilde{\sigma}=$ the standard deviation.

$\mathbf{n}=$ the number of animals.

in the lungs or viscera. Polymorphonuclear leucocytes were found in considerable numbers in the walls of the pulmonary and adrenal capillaries, presenting a picture similar to that seen in immunized animals injected intravenously with $\mathrm{Cl}$. welchii toxin (15).

\section{Cl. oedematiens toxin intramuscularly ( $8 \mathrm{dogs}$ )}

Following intramuscular injection of toxin into the thigh muscles in dosages ranging from 150 to 12,000 MLD per $\mathrm{kgm}$., there was a latent period of approximately 6 hours, during which little of significance was observed. From this time on there developed an increasing local edema which spread both up and down the thigh, eventually presenting itself in the retroperitoneal, gluteal, perineal, and neighboring regions. This edema became maximal at 18 to 24 hours, associated with a severe hemoconcentration, the hematocrit reaching values up to 75 . The animals became progressively sluggish, developed bloody diarrhea, and died 18 to 38 hours after injection. In $1 \mathrm{dog}$, injected with a 12,000 MLD per $\mathrm{kgm}$. dose of toxin, death occurred in 10 hours, and the amount of edema was not striking, amounting to 1 per cent of the body weight. This latter finding suggests that death of the animal cannot be accounted for on the basis of local fluid loss alone, but that a generalized toxemia is probably present when the intramuscular dose of toxin is enormous.

In 2 dogs injected with a 150 MLD per $\mathrm{kgm}$. dose of toxin, leg measurements were made, with the following results :

\begin{tabular}{c|c|c|c|c}
\hline \hline Dog no. & $\begin{array}{c}\text { Survival } \\
\text { time }\end{array}$ & $\begin{array}{c}\text { Terminal } \\
\text { edema (per } \\
\text { cent body } \\
\text { weight) }\end{array}$ & \multicolumn{2}{|c}{ Hematocrit } \\
\cline { 3 - 5 } & 17 hrs. & 5 & 50 & 73 \\
324 & 32 hrs. & 7 & - & 62 \\
\hline
\end{tabular}

The amount of edema was increased if the same quantity of toxin was injected fractionally into several sites.

In order to determine the minimum dosage of toxin which would produce edema by the intramuscular route, all 4 legs were injected in a single dog weighing $13 \mathrm{kgm}$. The volume of fluid injected into a single limb was kept constant at $5 \mathrm{ml}$. The dosage of toxin injected ranged, however, from $80 \mathrm{MLD}$ to $10 \mathrm{MLD}$ per $\mathrm{kgm}$. Eighteen hours later, there was massive edema (360 ml.) of the limb where the 80 MLD per kilogram dose had been given; moderate edema $(210 \mathrm{ml}$.) in the limb given $40 \mathrm{MLD}$ per $\mathrm{kgm}$.; minimal edema (70 ml.) in the limb with 20 MLD per kgm.; and no visibly recognizable edema ( $40 \mathrm{ml}$. by measurement) in the limb given 10 MLD per $\mathrm{kgm}$.

\section{Pathology associated with intramuscular injection of toxin}

Local effects: At the site of injection, there was an area approximately a centimeter in diameter where the muscle substance had been almost completely disintegrated. The surrounding muscle tissue was edematous, with separation of the muscle fibers by edema. Small, flame-shaped hemorrhages in countless number were present along 
the course of the dilated and engorged smaller branches of the blood vessels supplying muscle tissue near the injection site. Edema was greatest in the fascial spaces and subcutaneous tissue.

Distant effects: There was 20 to $30 \mathrm{ml}$. of strawcolored fluid in the pleural and peritoneal cavities. The lungs and visceral organs showed much the same picture although less pronounced than that produced by the intravenous route of injection.

\section{Effect on eyes}

One MLD of toxin was injected into the corneae of each of 4 rabbits' eyes. ${ }^{9}$ Eighteen hours after injection, there was marked chemosis of the conjunctival blood vessels. By means of slit lamp illumination and the high-power dissecting microscope, tiny flame-shaped hemorrhages were seen extending out from a number of the vessels. There were dilatation and engorgement of all vessels.

\section{DISCUSSION}

Experiments on the effect of $\mathrm{Cl}$. welchii toxic filtrates (14) have demonstrated that the dosage, rate, and route of administration of the toxins determine the type of effects on dogs. The same considerations apply to the present studies on $\mathrm{Cl}$. oedematiens toxin. Rapid intravenous administration of a large dose of toxin is a situation far different from the slow elaboration of the toxin by organisms multiplying in a damaged muscle. Intramuscular injection of a small, sub-lethal dose of toxin appears to approach the clinical situation most closely. Here the effect of the toxin is principally local, resulting in edema and hemoconcentration. Such a picture of $\mathrm{Cl}$. oedematiens myositis, predisposing to wound shock, has been observed in forward field hospitals (18).

The data gathered on the effects of this toxin after intravenous injection, are consistent with the interpretation that the principal site of its action is on the peripheral vascular system. The toxin appears to act by causing loss of tone and damage to capillaries and other small blood vessels. As a result, the smaller vessels of the lungs and viscera become engorged with blood which then extravasates into surrounding tissues. The quantity of

9 These experiments were carried out in collaboration with Dr. David Cogan. blood actively circulating is thereby decreased, and a fall in cardiac output occurs. There is a compensatory peripheral vasoconstriction, probably in the arterioles, resulting in an increased peripheral resistance. The extravasation of fluid and blood into the pulmonary alveoli produces an interference with oxygenation of the blood which eventually assumes critical proportions. The blood pressure remains unchanged until a point is reached where trapping of blood out of the active circulation and interference with oxygenation become too great for compensation. The blood pressure then falls to shock levels and death follows.

The possibility that the effects observed may be a non-specific foreign protein reaction is ruled out by the protective effect of antitoxin when given intravenously simultaneously with the toxin and by the complete protection against either intravenously or intramuscularly injected toxin provided by active immunization (17).

When the toxin is injected intravenously, blood vessels throughout the animal are exposed to the toxin, and the lungs and visceral organs suffer particularly. On intramuscular injection, however, blood vessels adjacent to the injection site are exposed first and come into contact with the greatest concentration of toxin. This correlates with the observation that edema into the injected area becomes the outstanding feature.

The clinical picture which this toxin produces when injected intravenously is that of shockapparently as a consequence of 2 factors: (1) trapping of whole blood in the viscera, rendering it unavailable to the circulation as a whole; and (2) extravasation of plasma and whole blood into vital organs through damaged capillaries. Addition of fluid to the circulatory system under these conditions does not restore the animal to normal, although it has a temporary beneficial effect until the additional fluid has likewise been lost from the circulation.

The inability of antitoxin to protect the animal when given more than a few minutes after the toxin suggests that the toxin produces some irreversible action on the blood vessel wall. One is tempted to reason from analogy with the action of $\mathrm{Cl}$. welchii alpha toxin that $\mathrm{Cl}$. oedematiens toxin (which appears to be protein in nature) may be an enzyme which acts on cell surfaces, destroy- 
ing some architectural unit of the surface structure. Once the damage is done, antitoxin may neutralize the effects of the toxin still circulating, but the initial damage is irreparable.

The possibility that myocardial failure might contribute to the circulatory failure has not been completely eliminated in these experiments. However, it has been shown by means of heart-lung preparations (19) that the cardiac ability and reserve are adequate up to the very end.

\section{SUMMARY}

$\mathrm{Cl}$. oedematiens toxin administered intravenously produced the following picture: a latent period of one or more hours without noticeable change, followed by a progressive rise in peripheral vascular resistance, a fall in cardiac output, and eventually a decline in blood pressure to shock levels and death. Edema and hemorrhage in the lungs and visceral organs were constant findings. $\mathrm{Cl}$. oedematiens toxin produced massive local edema, hemoconcentration, and eventual death, when administered intramuscularly in small dosage.

Intravenous fluids were of no permanent benefit in this syndrome. Under the conditions used, antitoxin did not prevent the lethal outcome if given more than 5 minutes after injection of the toxin.

The authors gratefully acknowledge the cooperation of Doctors Austin M. Brues and Alfred Pope in the early portion of this work. They are indebted to Mrs. Jean Rubin, Mrs. Barbara Barus, and to Miss Lydia Brewster for valuable technical assistance.

\section{BIBLIOGRAPHY}

1. MacLennan, J. D., Anaerobic infections of war wounds in the Middle East. Lancet, 1943, 2, 63, 94, 123.

2. Novy, F. G., Ein neuer anaërober Bacillus des malignen Oedems. Ztschr. f. Hyg. u. Infectionskrankh, 1894, 17, 209.

3. Weinberg, M., and Seguin, P., Le B. oedematiens et la gangrène gazeuse. Compt. Rend. Soc. de Biol., 1915, 78, 507.

4. Sacquépée, M. E., Etudes sur la gangrène gazeuse, Le bacille de l'oedème gazeux malin. Ann. Inst. Pasteur., 1916, 30, 76.

5. Guillaumie, M., Inhibition de l'effet protéolytique de la toxine oedematiens. Compt. rend. Soc. de Biol., 1942, 136, 479.

6. Favata, B. V., Dowdy, A. H., Sewell, R. L., and Vincent, J. G., The pathology of experimental clostridial infections in dogs. Surg., Gynec., Obst., 1944, 79, 660.

7. Aub, J. C., Brues, A. F., Dubos, R., Kety, S. S., Nathanson, I. T., Pope, A., and Zamecnik, P. C., Bacteria and the "toxic factor" in shock. War Med., .1944, 5, 71.

8. Nathanson, I. T., Nutt, A. L., Pope, A., Zamecnik, P. C., Aub, J. C., Brues, A. M., and Kety, S. S., The toxic factors in experimental traumatic shock. I. Physiologic effects of muscle ligation in the dog. J. Clin. Invest., 1945, 24, 829.

9. Brues, A. M., Cohn, W. E., Kety, S. S., Nathanson, I. T., Nutt, A. L., Tibbetts, D. M., Zamecnik, P. C., and Aub, J. C., The toxic factors in experimental traumatic shock. II. Studies on electrolyte and water balance in shock. J. Clin. Invest., 1945, 24, 835.

10. Kety, S. S., Nathanson, I. T., Nutt, A. L., Pope, A., Zamecnik, P. C., Aub, J. C., and Brues, A. M., The toxic factors in experimental traumatic shock. III. Shock accompanying muscle ischemia and loss of vascular fluid. J. Clin. Invest., 1945, 24, 839.

11. Aub, J. C., Brues, A. M., Kety, S. S., Nathanson, I. T., Nutt, A. L., Pope, A., and Zamecnik, P. C., The toxic factors in experimental traumatic shock. IV. The effects of the intravenous injection of the effusion from ischemic muscle. J. Clin. Invest., 1945, 24, 845.

12. Zamecnik, P. C., Aub, J. C., Brues, A. M., Kety, S. S., Nathanson, I. T., Nutt, A. L., and Pope, A., The toxic factors in experimental traumatic shock. V. Chemical and enzymatic properties of muscle exudate. J. Clin. Invest., 1945, 24, 850.

13. Pope, A., Zamecnik, P. C., Aub, J. C., Brues, A. M., Dubos, R. J., Nathanson, I. T., and Nutt, A. L., The toxic factors in experimental traumatic shock. VI. The toxic influence of the bacterial flora, particularly Clostridium zelchii, in exudates of ischemic muscle. J. Clin. Invest., 1945, 24, 856.

14. Zamecnik, P. C., Nathanson, I. T.; and Aub, J. C., Physiologic action of Clostridium welchii (Type A) toxins in dogs. J. Clin. Invest., 1947, 26, 394. 15. Ivy, A. C., Personal communication.

16. Klemperer, P., Penner, A., and Bernheim, A. I., The gastro-intestinal manifestations of shock. Am. J. Digest. Dis., 1940, 7, 410.

17. Nathanson, I. T., Levin, J., Aub, J. C., and Zamecnik, P. C., Unpublished data.

18. Stewart, J. D., and Warner, F., Observations on the severely wounded in forward field hospitals with special reference to wound shock. Ann. Surg., $1945,122,129$.

19. Krayer, O., Aub, J. C., Nathanson, I. T., and Zamecnik, P. C., The influence of antitoxin upon the action of Clostridium oedematiens toxin in the heartlung preparation of the dog. J. Clin. Invest., 1947, 26, 411.

20. Arkin, H., and Colton, R. R., An Outline of Statistical Methods, 4th edition. De Pamphilis Press, Inc., New York, 1939, p. 127. 